\title{
THERAPEUTIC EFFICACY OF ZINC OXIDE NANOPARTICLES IN DIABETIC RATS
}

\author{
Mohamed A. Kamel ${ }^{1}$, Mohamed H. Khairy ${ }^{1}$, Nada A. ELSadek ${ }^{1}$, \\ Mohamed M.A. Hussein ${ }^{2 *}$
}

${ }^{1}$ Department of Pharmacology, Faculty of Veterinary Medicine, Zagazig University, ${ }^{2}$ Department of Biochemistry, Faculty of Veterinary Medicine, Zagazig University, 44519, Egypt

*Corresponding author: Email: hamza_vet@yahoo.com

\begin{abstract}
This study attempted to scrutinize the potential efficacy of zinc oxide nanoparticles (ZnONPs) and the standard oral hypoglycemic drug glibenclamide in streptozotocin (STZ) -nicotinamide induced diabetic rats. Forty male Wistar rats were divided into four equal groups. Group 1 rats received saline orally and considered as a control group. Other groups were experimentally exposed to diabetes via intraperitoneal injection of STZ and group 2 was left as diabetic non-treated. Group 3 was orally administrated with ZnONPs at a low dose $(1 \mathrm{mg} / \mathrm{kg})$, and group 4 orally received glibenclamide $(600 \mu \mathrm{g} / \mathrm{kg})$ for 30 days (duration of the experiment). Blood glucose, insulin levels, lipogram profile and pancreatic antioxidant status were improved following ZnONPs or glibenclamide administration as compared to the diabetic group. Moreover, histopathological examination revealed a better outcome in the ZnONPs and glibenclamide treated groups. Although oral treatment of ZnONPs at a low dose $1 \mathrm{mg} / \mathrm{kg}$ body weight for 30 consecutive days had antidiabetic effect, this effect was less superior to glibenclamide. Therefore, further studies regarding increasing the dose of ZnONPs would be encouraging to get better anti diabetic effect.
\end{abstract}

Key words: Zinc oxide nanoparticles; antioxidant; diabetes; glibenclamide

\section{Introduction}

Diabetes mellitus (DM) is a metabolic disorder with chronic hyperglycemic and hypertriacylglycerolemic condition caused mainly due to defects in insulin secretion and/or action. The prevalence of diabetes is increasing rapidly worldwide (1). Zinc ( $\mathrm{Zn})$ is an essential micronutrient for pancreatic function through its effect on insulin stability and disturbance in $\mathrm{Zn}$ metabolism associated with diabetic complications (2). It is also a paramount player in the intracellular antioxidant machinery through its participation in the main antioxidant enzymes with free radical scavenging effect such as catalase, superoxide dismutase and metallothionein which attracted much attention in diabetes studies (3). Lower level of zinc in pancreatic tissues associated with lower insulin synthesis through $\beta$ cells (4). Elevated ROS can induce oxidative damage in pancreatic tissues with subsequent increased hyperglycemia (5).

The field of nanotechnology is one of the every foremost active analysis areas in fashionable materials science and biology $(6,7)$. Nano- 
particles come with new properties and biomedical applications which owed to its size, distribution and morphology (8).On the other hand, the use of nanoparticles has a dark side through their generation of reactive oxygen species (ROS), resulting in oxidative damage and inflammation $(9,10)$. Zinc oxide nanoparticles (ZnONPs) are widely used in paint, pharmaceutical industry, and cosmetic industries; furthermore, they have antimicrobial action (11). The harmful effects of ZnONPs could be detected through increasing the expression of adhesion molecules in endothelial cells, resulting in inflammation $(12,13)$. High dose of ZnONPs was used as a new anti diabetic agent (14) but at the same time this higher dose led to release of $\operatorname{ROS}(15,16)$. However, the potential effect of ZnONPs low dose on diabetes has not been elucidated yet.

Therefore, the present study was designed to investigate the potential therapeutic efficacy of ZnONPs at low dose, relative to glibenclamide as a standard oral hypoglycemic drug, on diabetic rats with regard to lipogram profile and antioxidant status in addition to the histopathological picture of the pancreas.

\section{Material and methods}

\section{Drugs and chemicals}

Zinc oxide nanoparticles (ZnONPs) were obtained from the Faculty of Science, Department of Physics, Zagazig University in the form of dispersion. The average nanoparticle size was less than $50 \mathrm{~nm}$ as detected by transmission electron microscope (Fig.1). The ZnONPs distribution was detected using dynamic light scattering (DLS) technique, $\mathrm{pH} 7 \pm 0.1$ for aqueous systems and density $1.7 \mathrm{~g} / \mathrm{ml} \pm 0.1$ at $25^{\circ} \mathrm{C}$. The standard anti diabetic drug glibenclamide was used under a trade name of Daonil ${ }^{\circledR}$, (Sanofi Avents Co. for Pharmaceutical Industries, Egypt, $5 \mathrm{mg}$ active ingredient per tablet). Streptozotocin (STZ) was purchased from Sigma Chemicals Co., St. Louis, MO, USA.

\section{Animals}

Forty male Wistar rats, 2 months old and average body weight of $150 \pm 20 \mathrm{gm}$, were housed in metal cages at $\left(23 \pm 2^{\circ} \mathrm{C}\right)$ with a light-dark
(12:12 h) cycle and food and water ad libitum. Animals were kept two weeks before starting the experiment to be accommodated under laboratory condition. The guidelines and ethical rules of Zagazig Veterinary Medicine have been followed.

\section{Experimental design}

Animals were allocated into 4 equal groups (10 animals per group). The $1^{\text {st }}$ group was considered as a control and received only saline solution. Second group was diabetic, non-treated while the $3^{\text {rd }}$ and $4^{\text {th }}$ groups were diabetic rats and orally received $1 \mathrm{mg} / \mathrm{kg}$ body weight ZnONPs (17) and $600 \mathrm{mg} / \mathrm{kg}$ body weight glibenclamide (18) for 30 days using stomach tube.

Type 2 diabetes was induced by single intraperitoneal injection of a freshly prepared solution of streptozotocin $(60 \mathrm{mg} / \mathrm{kg}$ dissolved in citrate buffer $\mathrm{pH} 4.5$ ) then after fifteen minutes, nicotinamide $(95 \mathrm{mg} / \mathrm{kg}$ ) dissolved in saline was intraperitoneally injected (19). Rats were allowed to drink $10 \%$ glucose solution over night to overcome drug-induced hypoglycemia. Rats were considered diabetic when their blood glucose reached above $250 \mathrm{mg} / \mathrm{dl}$. The animals were considered diabetic when their blood glucose levels became above $250 \mathrm{mg} / \mathrm{dl}$ on the $3^{\text {rd }}$ day after STZ injection.

\section{Blood biochemical parameters}

At the end of the experiment (after 30 days), blood samples were collected from the medial canthus of the eye in either EDTA coated tubes (for determination of blood glucose) or plain tubes (for serum biochemical analysis). Blood glucose values were recorded using commercially available kits following manufacturer's instructions (20). Serum insulin levels were evaluated using commercially available ELISA kit. Serum triglyceride, total cholesterol, Highdensity-Lipoprotein cholesterol (HDL-c), low density lipoprotein cholesterol (LDL-c), and very low density lipoproteins (VLDL) were determined by the methods described by (21-24). 
Antioxidant status and oxidative stress assay

After euthanization, the spleen was quickly excised, rinsed with saline and tissue homogenate was prepared as previously described (25). The obtained supernatant from pancreatic homogenate was used for determination of antioxidant enzymes activities [glutathione peroxidase (GPx), catalase (CAT), and superoxide dismutase (SOD)] and lipid peroxidation (LPO) contents as previously described (26-28).

\section{Histopathological examination of pancreas}

Samples from the pancreas of all groups were collected and fixed in $10 \%$ neutral formalin for $24 \mathrm{~h}$ prior to routine processing in paraffin wax. Samples were cut into $5 \mu \mathrm{m}$ sections. Slides were stained with Hematoxylin \& Eosin (H\&E) and examined microscopically.

For morphometric analysis of the Islets diameter, Islets were isolated by a modification of the automated method described by (29). In each animal one slide was stained and 25 images/group were taken using Am Scope 5.0 MP microscope digital camera at $400 \mathrm{X}$ magnification. Islets diameters were measured by using Mitocam ${ }^{\circledR}$ plus 2.0 (Motic Images plus 2.0, china) and Islets cells were counted using Image 1.45s software (National Institute of Health USA).

\section{Data analysis}

Data were expressed as mean \pm standard error (SE). Difference between groups was detected using one way ANOVA followed by Duncan's Multiple Range Test using SPSS version 21 . Values at $\mathrm{P}<0.05$ were considered statically significant.

\section{Results}

Effect ZnONPs and glibenclamide on blood glucose and serum insulin levels

Blood glucose and serum insulin levels were significantly elevated in STZ treated animals as compared to the control animals (Table1). Both $\mathrm{ZnONPs}$ and glibenclamide treated animals exerted a significant decrease in blood glucose levels as compared to STZ-treated animals.
However, among the treated rats, glibenclamide treatment showed better results than ZnONPs.

Effect ZnONPs and glibenclamide on lipid profile parameters

STZ treated animals exhibited a significant higher serum levels of total cholesterol (TC), triglyceride (TG), LDL-c and VLDL and a significant lower HDL-c level relative to the control group (Table 1). In contrast, ZnONPs and glibenclamide treated groups exerted a significant decrease in TC, TG, LDL-c and VLDL and a marked increase in HDL-c compared to STZ treated animals. Glibenclamide evoked a better result compared to $\mathrm{ZnONPs}$ treated rats.

\section{Effect ZnONPs and glibenclamide on antiox- idant/oxidative status}

Antioxidant scavenging potentials for ZnONPs and glibenclamide treated animals were figured out in Table 2. The diabetic group showed a marked decrease in antioxidant enzymes (SOD, GPx, and CAT) activities and a significant increase in lipid peroxidation marker MDA. However, ZnONPs and glibenclamide treated groups exerted a significant increase in antioxidants (SOD, GPx, and CAT) activities and decrease in MDA levels as compared to diabetic animals.

\section{Histopathological examination}

Examined sections revealed normal size, population and structures of the pancreatic cells, normal Langerhans islet components in the control group (Fig., 2A). However, pancreas of diabetic rats showed degenerative changes, cytoplasmic vacuolation, apoptosis and hypo-cellularity of most of $\beta$-cells of islets of Langerhans, but alpha cells were normal in most parts (Fig., 2B). Pancreas of rats treated with glibenclamide showed normal histologic appearance with normal size, population and structures with mild congestion of islets capillaries (Fig., 2C). Pancreas of rats treated with ZnONPs showed apparently normal islet cells with preserved size and cellular population, with a few cells either apoptotic or hypertrophied (Fig. 2D). 
Table 1: The Effect of ZnONPs and glibenclamide on lipid profile, blood glucose and insulin level on healthy and diabetic rats

\begin{tabular}{|c|c|c|c|c|c|c|c|}
\hline Group & $\begin{array}{c}\text { Total cho- } \\
\text { lesterol } \\
(\mathrm{mg} / \mathrm{dl})\end{array}$ & $\begin{array}{l}\text { Triglyceride } \\
\text { (mg/dl) }\end{array}$ & $\begin{array}{l}\text { HDL-c } \\
(\mathrm{mg} / \mathrm{dl})\end{array}$ & $\begin{array}{l}\text { LDL-c } \\
(\mathrm{mg} / \mathrm{dl})\end{array}$ & $\begin{array}{l}\text { VLDL } \\
(\mathrm{mg} / \mathrm{dl})\end{array}$ & $\begin{array}{l}\text { Blood glu- } \\
\text { cose } \\
(\mathrm{mg} / \mathrm{dl})\end{array}$ & $\begin{array}{l}\text { Insulin } \\
(\mu \mathrm{Iu} / \mathrm{ml})\end{array}$ \\
\hline$\overline{\text { Control }}$ & $\begin{array}{c}195.66 \pm \\
2.33^{c}\end{array}$ & $120.33 \pm 3.17^{\mathrm{d}}$ & $\begin{array}{c}57.33 \pm \\
4.48^{\mathrm{a}}\end{array}$ & $\begin{array}{c}137.64 \pm \\
4.09^{\mathrm{d}}\end{array}$ & $24.06 \pm .64^{\mathrm{d}}$ & $\begin{array}{l}101.8^{ \pm} \\
10.29^{\mathrm{c}}\end{array}$ & $2.82 \pm$ \\
\hline Diabetic & $\begin{array}{c}295.28 \pm \\
6.87^{\mathrm{a}}\end{array}$ & $186.85 \pm 2.38^{\mathrm{a}}$ & $\begin{array}{c}26.71 \pm \\
1.64^{\mathrm{c}}\end{array}$ & $\begin{array}{c}284.20 \pm \\
5.06^{\mathrm{a}}\end{array}$ & $37.37 \pm .48^{\mathrm{a}}$ & $\begin{array}{c}335.6 \pm \\
6.15^{\mathrm{a}}\end{array}$ & $0.90 \pm 0.045^{\mathrm{d}}$ \\
\hline $\begin{array}{l}\text { Diabetic treated } \\
\text { with ZnONPs }\end{array}$ & $\begin{array}{c}241.66 \pm \\
4.40^{\mathrm{b}}\end{array}$ & $154.66 \pm 2.90^{\mathrm{b}}$ & $\begin{array}{c}34.66 \pm \\
2.60^{\mathrm{c}}\end{array}$ & $\begin{array}{c}214.96 \pm \\
7.04^{\mathrm{b}}\end{array}$ & $30.93 \pm .34^{\mathrm{c}}$ & $\begin{array}{r}231.8 \pm \\
6.15^{\mathrm{b}}\end{array}$ & $1.24 \pm 0.035^{c}$ \\
\hline $\begin{array}{l}\text { Diabetic treated } \\
\text { with glibenclamide }\end{array}$ & $\begin{array}{c}226.25 \pm \\
4.09^{\mathrm{b}}\end{array}$ & $137.50 \pm 1.70^{c}$ & $\begin{array}{c}47.250 \pm \\
2.3^{\mathrm{b}}\end{array}$ & $\begin{array}{c}181.54 \pm \\
5.68^{c}\end{array}$ & $30.93 \pm .58^{\mathrm{b}}$ & $\begin{array}{l}221.2^{ \pm} \\
3.70^{\mathrm{c}}\end{array}$ & $1.95 \pm 0.054^{b}$ \\
\hline
\end{tabular}

Means within the same column carrying different superscripts are significantly different at $\mathrm{P}<0.05$

Table 2: The Effect of ZnONPs and glibenclamide on pancreatic antioxidant/oxidative stress status on healthy and diabetic rats

\begin{tabular}{lcccc}
\hline \multicolumn{1}{c}{ Group } & $\begin{array}{c}\text { CAT } \\
\text { (U/gm tissue) }\end{array}$ & $\begin{array}{c}\text { MDA } \\
(\text { nmol/gm tissue })\end{array}$ & $\begin{array}{c}\text { SOD } \\
(\text { nmol/gm tissue })\end{array}$ & $\begin{array}{c}\text { GPx } \\
(\text { U/gm tissue })\end{array}$ \\
\hline Control & $199.79 \pm 5.681^{\mathrm{a}}$ & $5.623 \pm 0.253^{\mathrm{c}}$ & $21.040 \pm 1.185^{\mathrm{a}}$ & $116.33 \pm 1.789^{\mathrm{a}}$ \\
Diabetic & $125.165 \pm 3.200^{\mathrm{c}}$ & $22.667 \pm 1.015^{\mathrm{a}}$ & $4.468 \pm 0.322^{\mathrm{d}}$ & $65.200 \pm 2.279^{\mathrm{d}}$ \\
Diabetic, ZnONPs treated & $161.48 \pm 4.015^{\mathrm{b}}$ & $15.323 \pm 1.433^{\mathrm{b}}$ & $9.656 \pm 1.258^{\mathrm{c}}$ & $87.69 \pm 4.614^{\mathrm{c}}$ \\
Diabetic, glibenclamide treated & $193.43 \pm 4.768^{\mathrm{a}}$ & $8.837 \pm 1.236^{\mathrm{c}}$ & $15.017 \pm 0.933^{\mathrm{b}}$ & $101.590 \pm 3.398^{\mathrm{b}}$ \\
\hline
\end{tabular}

Means within the same column carrying different superscripts are significantly different at $\mathrm{P}<0.05$

Table 3: Lesion scores of different changes related to islets of Langerhans among experimental groups

\begin{tabular}{|c|c|c|c|c|c|c|c|c|}
\hline$\frac{\mathscr{0}}{\tilde{0}}$ & 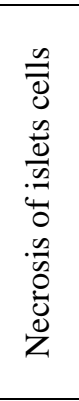 & $\begin{array}{l}n \\
0 \\
0 \\
0 \\
0 \\
0 \\
0 \\
0 \\
0 \\
0 \\
0 \\
0 \\
0 \\
0 \\
0 \\
0\end{array}$ & $\begin{array}{l}0 \\
\overline{0} \\
0 \\
0 \\
0 \\
0 \\
0 \\
0 \\
0 \\
0 \\
0 \\
0 \\
0 \\
0 \\
0 \\
0 \\
0 \\
0\end{array}$ & 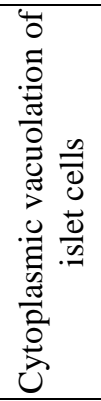 & 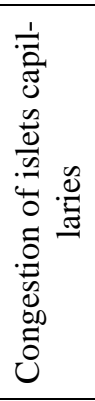 & 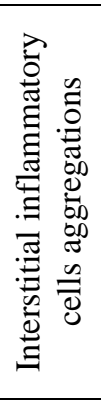 & 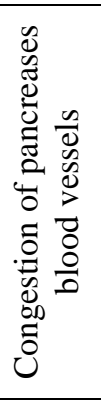 & 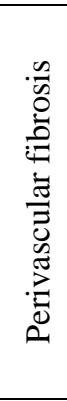 \\
\hline Control & - & - & - & - & - & - & - & - \\
\hline Diabetic, non-treated & +++ & +++ & +++ & +++ & - & - & +++ & +++ \\
\hline Diabetic, ZnONPs treated & + & ++ & ++ & ++ & +++ & +++ & - & - \\
\hline Diabetic, glibenclamide treated & - & - & - & - & + & - & - & - \\
\hline
\end{tabular}

(-=No, +=Mild, ++=Moderate, $+++=$ Severe) 


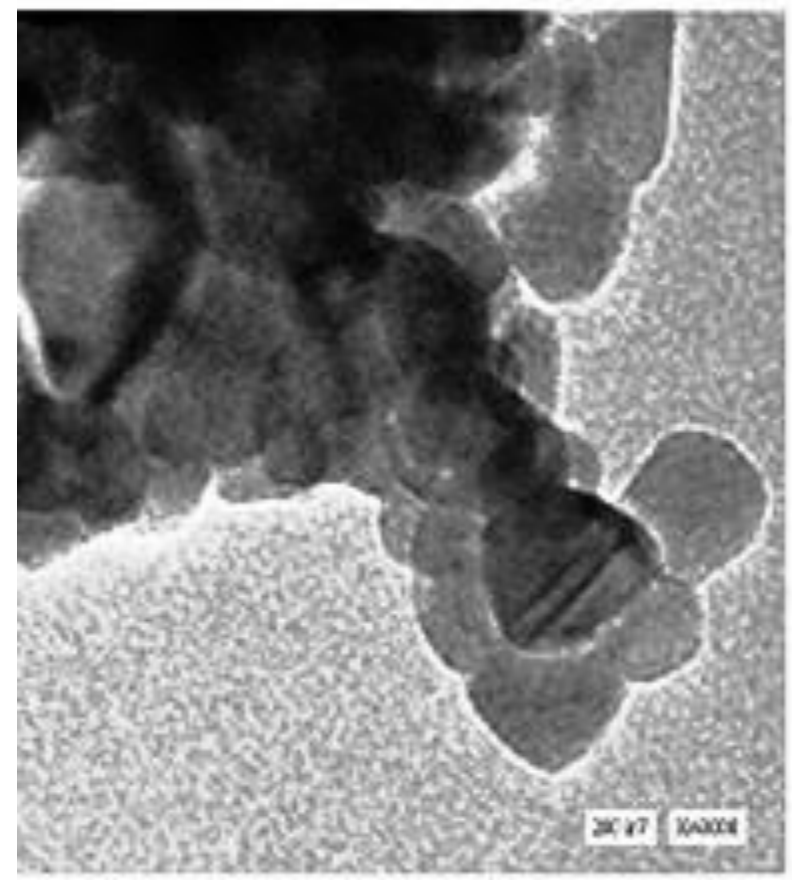

Figure 1: Transmission Electron Micrograph (TEM) image of ZnONPs. The beam of electrons transmitted through the specimen shows $50 \mathrm{~nm}$

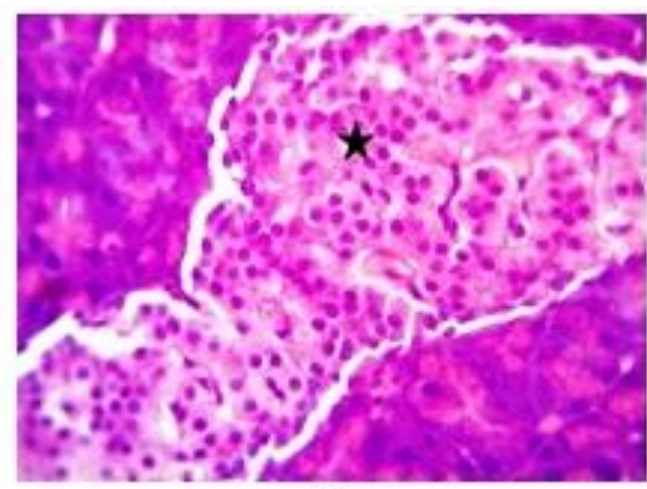

A

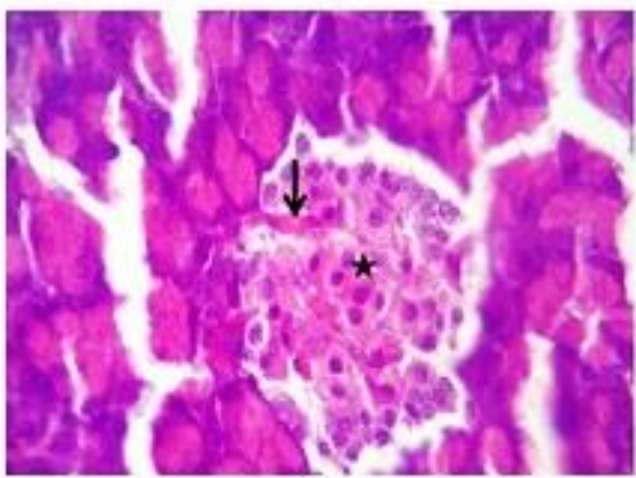

C

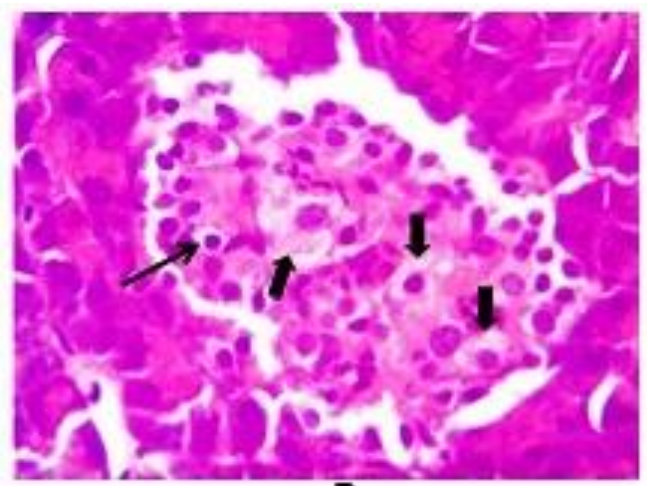

B

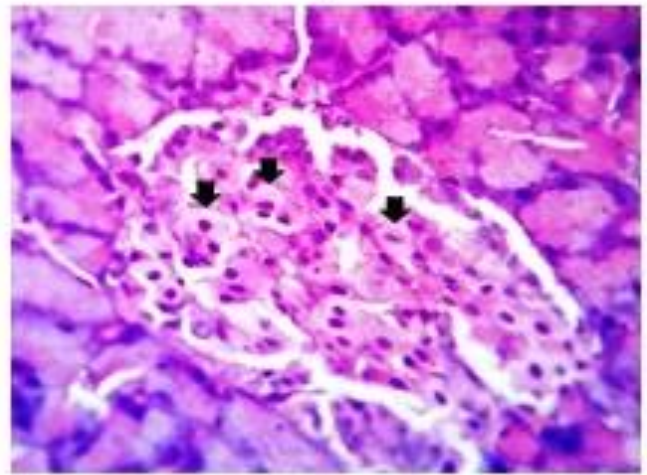

D

Figure 2: Photomicrograph of pancreatic tissues of experimental groups. A) Normal Langerhans islet components (star) in the control rat H\&E X400. B) Diabetic rat pancreas shows hypo-cellularity of Langerhans with cytoplasmic vacuolation (thick arrows) and apoptosis (thin arrow). C) Pancreas of rat treated with glibenclamide shows normal islets structures (star) with mild congestion of islets capillaries (thin arrow). D) Pancreas of rat treated with ZnONPs shows apparently normal with preserved size and cellular population, with a few cells either apoptotic or hypertrophied (thick arrows). H\&E X400 


\section{Discussion}

The pathogenesis of type 2 diabetes relays on insulin resistance and chronic hyperglycemia and hyper triacylglycerolemia (30). The enhanced role of $\mathrm{Zn}$ in diabetes mellitus pathogenesis especially through its effect on insulin synthesis $(15,31)$ makes correction of zinc imbalance a matter of essence where the easily passage of oral administered nanoparticles through biological membranes makes them a promising therapeutic agent $(14,32)$. In the present study, we observed a significant increase in blood glucose levels in diabetic rats. This may be due to the destruction of pancreatic beta cells by STZ. This reinforces the fact that STZ induces diabetes probably through the generation of oxygen free radicals (33). The elevation of glucose in rats received STZ was due to an oxidative stress produced in the pancreas and also probably due to a single strand break in pancreatic islet DNA (34). Our results showing that oral administration of ZnONPs to STZ diabetic rats revealed a significant decrease in blood glucose levels. Rinku and Paknikar (35) results were in agreement with our results. Glibenclamide treatment showed better results when compared to ZnONPs treated group.

The significant role of insulin as a hypoglycemic hormone owed to its ability to stimulate glucose oxidation and storage of it either in the form of glycogen and triglyceride in adipose tissue (36). The inability of skeletal muscle, adipose tissue, liver and peripheral tissues to respond to insulin results in insulin resistance which is the core for type 2 diabetes pathogenesis. The pancreas is able to produce sufficient levels of insulin to maintain glucose levels beneath the diabetic threshold (37). In the present study, STZ diabetic rats showed marked depletion in serum insulin. STZ causes diabetes by the rapid depletion of $\beta$-cells; thereby bring about a reduction in insulin release. The oral administration of low dose ZnONPs or glibenclamide to STZ diabetic rats revealed a significant improvement in serum levels in insulin. This indicates ZnONPs and glibenclamide ability to improve insulin sensitivity and increased glucose utilization $(15,34)$. Again the best ant diabetic effect was noticed in rats treated with glibenclamide. The latter has the ability to increase pancreatic beta cells production of insulin. The long duration of glibenclamide action and its metabolites could increase its prolonged hypoglycemic risk (18).

The chronic diabetic state was also associated with dyslipidemia. Administration of STZ caused an increase in serum TC and TG (37). Similarly, we found that STZ-diabetic rats showed a marked increase in lipid profile parameters, TC, TG, LDL and VLDL, while there was a marked reduction in serum HDL-c. On a similar basis, Rinku and Paknikar, (34) found a marked elevation in serum TG following STZ administration. Oral treatment of STZ-diabetic rats with low dose of ZnONPs and glibenclamide evoked a significant decrease in serum TC, TG, LDL and VLDL but with a marked increase in serum HDL-c. Consistent with our findings, a marked reduction in lipid profile parameters following treatment with ZnONPs at $3 \mathrm{mg}$ and $10 \mathrm{mg} / \mathrm{kg}$ was also reported in diabetic rats by another study (15).

Oxidative stress is defined as an imbalance between cellular production of oxidant molecule and the availability of appropriate anti-oxidants that defend against them (38). Continued oxidative stress leads to the development of chronic diseases, including diabetes mellitus, cancer, neuro-degeneration, cardio vascular and metabolic disease (39). Herein, we found that administration of STZ resulted in an observable increase in lipid peroxidation marker MDA levels and a significant decrease in the anti-oxidant activity of GPx, CAT, and SOD in pancreas as compared to the control rats. Similarly, a significant increase in hepatic and renal MDA, with a marked reduction in hepatic and renal GPx, CAT, and SOD activities were also reported in diabetic rats (20). In contrast, oral administration of ZnONPs or glibenclamide to diabetic rats showed an increase in GPx and CAT activities, with better results with glibenclamide, relative to diabetic untreated rats. Interestingly, the oral treatment with higher doses of ZnONPs ( 3 and 10mg) also produced a marked reduction in pancreatic GPx 
and CAT activities in comparison to diabetic non treated rats $(15,40)$.

In the present study, STZ administration revealed degenerative changes, cytoplasmic vacuolation, apoptosis and hypo-cellularity of most of $\beta$-cells of islets of Langerhans, but alpha cells were normal in most parts. Similarly, Daisy et al., (41) found altered islet structure in rats treated with STZ at a dose of 40 and $50 \mathrm{mg} / \mathrm{kg}$ body weight. Histopathological examination revealed a better outcome in the ZnONPs and glibenclamide treated groups.

\section{Conclusion}

Oral treatment of ZnONPs at a low dose $1 \mathrm{mg} / \mathrm{kg}$ body weight for 30 consecutive days had anti diabetic effect. However, this effect was less superior to glibenclamide and hence further studies regarding increase the dose of ZnONPs would be encouraging.

\section{Conflict of interest statement}

None.

\section{Acknowledgments}

This work was supported by the Faculty of Veterinary Medicine, Zagazig University, Egypt. The authors thank Dr. Mohamed Metwally, assistant professor of pathology, Faculty of Veterinary Medicine, Zagazig University for his support in histopathological examination.

\section{References}

1. Njolstad PR, Sagen JV, Bjorkhaug L, Odili S, Shehadeh N, Bakry D, Sarici SU, Alpay F, Molnes J, Molven A, Sovik O, Matschinsky FM. Permanent neonatal diabetes caused by glucokinase deficiency: inborn error of the glucose-insulin signaling pathway. Diabetes 2003; 52 (11): 2854-60.

2. Wolfgang M. Zinc in pancreatic islet biology, insulin sensitivity, and diabetes. Prev. Nutr. Food Sci. 2017; 22 (1): 1-8.

3. Masaki H, Ochiai Y, Okano Y, Yagami A, Akamatsu H, Matsunaga K, Sakurai H, Suzuki KJ. A zinc (II) - glycine complex is an effective inducer of metallothionein and removes oxidative stress. Dermatol. Sci. 2007; 45: 73-5.

4. Huang SH, Seet RC, Lee CY, Lim EC, Quek AM, Looi WF, Long LH, Halliwell B. Oral zinc supplementation does not improve oxidative stress or vascular function in patients with type 2 diabetes with normal zinc levels, Atherosclerosis 2011; 219: 231-9.

5. Meyer JA, Spence DM. A perspective on the role of metals in diabetes: past findings and possible future directions, Metallomics 2009; 1: 32-41.

6. Zak AK, Razali R, Majiid WH, Darroudi M. Synthesis and characterization of an arrow size distribution of zinc oxide nanoparticles. Int. J. Nanomed. 2011; 6: 1399-1403.

7. Chaudhuny K, Kumer V, Kandasamy J, Roy CS. Regenerative nano-medicine: current perspectives and future directions. Int. J. Nanomed. 2014; 9: 4153-67.

8. Talylor E, Webster TJ. Reducing infections through nanotechnology and nanoparticles, Int. J. Nanomed. 2011; 6: 1463-73.

9. Xia T, Kovochich M, Brant J, Hotze M, Sempf J, Oberley T, Sioutas C, Yeh JI, Wiesner MR, Nel AE. Comparison of the abilities of ambient and manufactured nanoparticles to induce cellular toxicity according to an oxidative stress paradigm. Nano Lett. 2006; 6: 1794-807.

10. Nel AE, Mädler L, Velegol D, Xia T, Hoek EM, Somasundaran P, Klaessig F, Castranova V, Thompson M. Understanding biophysicochemical interactions at the nano-bio interface Nat. Mater. 2009; 8: 543-57.

11. Shirgholami M, Nazari A, Mirjalili M. Statistical optimization of self - cleaning technology and color reduction in wool fabric by nano zinc oxide and eco-friendly cross- linker. Clean Technol. Environ. Policy 2015; 17 (4): 905-19.

12. Gojova A, Guo BR,Kota RS, Rutledge JC, Kennedy IM, and Barak AI. Induction of inflammation in vascular endothelial cells by metal oxide nanoparticles: effect of particle composition. Environ. Health Pro. 2007; 115: 403-9.

13. Tsou TC, Yeh SC, Tsai FY, Lin HJ, Cheng TJ, Chao HR, Tai LA. Zinc oxide particles induce inflammatory responses in vascular endothelial cells via NF- $\mathrm{kB}$ signaling. J. Hazard. Mater. 2010; 183 (1-3): 182-8.

14. Umrani RD, Paknikar KM. Zinc oxide nanoparticles show antidiabetic activity in streptozotocin-induced Type 1 and 2 diabetic rats. Nano medicine (Lond). 2014; 9 (1): 89-104.

15. Hussein MM, Ali HA, Saadeldin IM, Ahmed MM. Querectin Alleviates Zinc Oxide Nanoreprotoxicity in Male Albino Rats. J Biochem Mol Toxicol. 2016; 30(10):489-96.

16. Rydberg T, Jönsson A, Karlsson MO, Melander A. Concentration-effect relations of glibenclamide and its active metabolites in man: 
modeling of pharmacokinetics and Pharmacodynamics. Br. J. Clin. Pharmacol. 1997; 43: 373-81.

17. Asri-Rezaei S, Dalir-Naghadeh B, Nazarizadeh A, Noori-Sabzikar Z. Comparative study of cardio-protective effects of zinc oxide nanoparticles and zinc sulfate in streptozotocin-induced diabetic rats. J. Trace. Elem. Med. Biol. 2017; 42: 129-41.

18. Kamel MA. Protective effects of marjoram oil (Organiam majorana L,) on anti-oxidant enzymes in experimental diabetic rats. Assuit Vet. Med. J. 2014; 60 (140): 68-74.

19. Sithole HL. A review of the use of streptozotocin (STZ) in the induction of diabetes in rats and subsequent ocular tissue changes. Afr. Vision Eye Health 2009; 68 (2): 82-8.

20. Trinder P. Enzymatic determination of glucose. Ann. Clin. Biochem. 1969; 6: 24.

21. Fletcher MJ. A colorimetric method for estimating serum triglycerides. Clin. Chim. Acta. 1968; 22: 393-7.

22. Finley PR, Schifman RB, Williams RJ, Lichti DA. Cholesterol in high-density Lipoprotein: use of $\mathrm{Mg} 2+/$ dextran sulfate in its enzymatic measurement. Clin. Chem. 1978; 24: 931-3.

23. Gazi I, Tsimihodimos V, Filippatos TD, Saougos VG, Bairaktari ET, Tselepis AD, Elisaf M. LDL cholesterol estimation in patients with the metabolic syndrome. Lipids Health Dis. 2006; 5: 8.

24. Friedwaid WT, Levy RI, Fedreicson DS. Estimation of the concentration of low-density lipoprotein cholesterol in plasma, without of the preparative ultracentrifuge. Clin. Chem. 1972; 18: 499506.

25. Abdelhady, D.H., El-Magd, M.A., Elbialy, Z.I., Saleh, A.A., 2017. Bromuconazole-induced hepatotoxicity is accompanied by upregulation of PXR/CYP3A1 and downregulation of CAR/CYP2B1 gene expression. Toxicol Mech Methods 27, 544-50.

26. Aebi H. Catalase, In: Bergmeryer H.U. and Ulrich H. "Methods of Enzymatic Analysis" 2nd ed., Verlag: Chemic, Weinhein, New York, 1974; 673.

27. McCord JM, Fridovich I. Superoxide dismutase. An enzymatic function for erythrocuprein (hemocuprein). J. Biol. Chem. 1969; 244 (22): 6049-55.

28. Nielsen F, Mikkelsen BB, Nielsen JB, Andersen HR, Grandjean P. Plasma malondialdehyde as biomarker for oxidative stress. Reference interval and effects of lifestyle factors. Clin. Chem. 1997; 43 (7): 1209-14.
29. Ricordi C, Rastellini C. Methods in pancreatic islets separation. In: Ricordi C. Editor. Methods in Cell Transplantation. Austin, TX: R.G. Landes 1995; 433-8.

30. Wild SG, Green A, Sicrec R, King H. "Global prevalence of diabetes: estimates for the year 2000 and projections for 2030", Diabetes care 2004; 27 (5): 1047-53.

31. Ukperoro JU, Offiah N, Idris T, Awogoke D. Antioxidant effect of zinc, selenium and their combination on the liver and kidney of alloxan-induced diabetes in rats. Med. J. Nutr. Metab. 2010; 3 (1): 25-30.

32. Moustafa SA. Zinc might protect oxidative changes in the retina and pancreas at the early stage of diabetic rats. Toxicol. Appl. Pharmacol. 2004; 201: 149-55.

33. Gupta S, Kataria M, Gupta PK, Mugandan S, Yash RC. Protective role of extracts of neem seeds indiabetes caused by streptozotocin in rats. J. Ethnopharmacol. 2004; 90: 185-9.

34. Yamamoto Y, Ford RC, Barber J. Relationship between thylakoid membrane fluidity and the functioning of pea chloroplasts: Effect of cholesteryl hemisuccinate. Plant Physiol. 1981; 67: 1069-72.

35. Rinku DU, Paknikar MK. Zinc oxide nanoparticles show antidiabetic activity in streptozotocin-induced Type 1 and 2 diabetic rats. Nanomedicine 2013; 9(1): 89-104.

36. Raju SM, Raju B. Illustrated Medical Biochemistry. 2010; 2nd Edition, Jaypee Brothers Medical Publishers Ltd., New Delhi.

37. Manschot SM, biessels GJ, Rutten GE, Kessels RC, Gispen WH, Kappelle LJ. Peripheral and central neurologic complications in type 2 diabetes mellitus: no association in individual patients. J. Neurol Sci. 2008; 264 (1-2): 157-62.

38. Ahrén B. Type 2 diabetes, insulin secretion and beta-cell mass. Curr. Mol. Med. 2005; 5 (3): 275-86.

39. Elahi MM, Kong YX, Matata BM. Oxidative stress as a mediator of cardiovascular disease. Oxid. Med. cell. long. 2009; 2: 259-69.

40. Huang J, Das SK, Jha P, Alzoughi W, Schauor S, Claudel T, Sexal V, Vesely P, Birner Gruenberger R, Krutky D, Michael T, Gerald H. The PPAR $\alpha$ agonist fenofibrate suppresses B-cell lymphoma in mice by modulating lipid metabolism. Biochim. Biophys. Acta. 2013; 1831(10): 1555-65.

41. Daisy MM, Rashmi V, Akila G, Gunasekaran S. Effect of streptozotocin on the ultrastructure of rat pancreatic islets. Microsc. Res. Tech. 2004; 63 (5): 274-81. 